\title{
Intervenção do estado sobre o domínio econômico por meio da extrafiscalidade em prol da segurança ambiental ${ }^{1}$
}

\author{
State intervention on the economic domain through extrafiscality in support of \\ environmental safety
}

\author{
Isabella Faddul de Almeida ${ }^{2}$ \\ Marlene Kempfer Bassoli ${ }^{3}$
}

\section{Resumo}

O conceito tradicional de Segurança em foco estatocêntrico, atualmente, pode ser substituído pela Segurança Humana, que tem como sujeito o indivíduo e não mais o Estado. Traz um foco humanocêntrico preocupando-se com os direitos humanos e a sustentabilidade. Em 1994, o Programa de Desenvolvimento das Nações Unidas (PNDU) definiu em seu relatório anual e conceito de segurança humana e identificou como uma das dimensões de segurança, a segurança ambiental que enfatiza a proteção e preservação do meio ambiente em face do rápido crescimento populacional, industrial, produção que sobrecarrega as terras, contaminação do ar, falta de água e aquecimento global. No ordenamento jurídico brasileiro tem-se, em nível constitucional, positivado a dimensão da segurança ambiental, conforme se constata pela leitura dos artigos 170, VI, 186, I e II e art. 225. Assim, tem-se autorização constitucional para que o Estado faça sua parte e viabilize este enfoque de Segurança Humana. Entre as iniciativas possíveis para a concretização da segurança ambiental, destaca-se as políticas públicas tributárias ambientais dirigidas às atividade econômicas, por meio de incentivos, dando efetividade a norma constitucional do art. 170, IV da Constituição Federal.

Palavras Chave: Segurança humana; Segurança ambiental; Intervenção do Estado; Tributação; Extrafiscalidade.

Abstract

The traditional concept of security threats involved in protecting the rule gave way to a security that aims at protecting the individual, bringing a human focus, who cares about human rights and sustainability. In 1994, the United Nations Development Programme (UNDP) in its annual report defined the concept of human security and identified as one of the dimensions of security, environamental securuty. Environmental security is focused on the protection and preservation of

\footnotetext{
Artigo produzido a partir do Trabalho de Conclusão de Curso (TCC) de graduação em Direito na PUCLondrina/Pr.

2 Advogada, aluna do curso de especialização em Direito Ambiental e Urbanístico pela Universidade Anhanguera-Uniderp em parceria com a Rede LFG

3 Professora da graduação e pós graduação da Universidade Estadual de Londrina, Puc-Londrina/PR. e UNIMAR/SP
} 
environmental damage arising from rapid population growth, industrialization, intensive production that overwhelms the land, air pollution, water shortages, salinization, desertification and global warming. In the Brazilian legal system has, in the constitutional level, the size of positivised Environmental Safety as noted by reading the articles $170, \mathrm{VI}, 186, \mathrm{I}$ and $\mathrm{II}$ and 225 . Thus, it has constitutional authorization for governments to do their part as allowing this form of human security. Possible initiatives are the environmental tax policies directed at economic activities, through incentives, giving effectiveness to constitutional provision of Article 170, IV of the Constitution.

Keywords: Human Security, Environmental Security, State intervention, taxation, regulatory taxes

\section{Introdução}

As relações humanas transformam-se, portanto, para suprir as necessidades humanas faz-se necessário analisar os valores sociais de cada época. A partir desta premissa, na contemporaneidade, o conceito tradicional de Segurança Humana com foco estatocêntrico, que considera apenas a proteção das ameaças ao Estado, deve ser revisto. A mudança deve considerar uma acepção humanocêntrica, ou seja, construir um conceito tendo em vista as necessidades humanas de modo a realizar direitos frutos de conquistas ao longo de séculos.

Entre as diferentes concepções sobre Segurança Humana trazidas por Juan Pablo Fernández Pereira no ano de 2006, em sua obras "La Seguridad Humana Un Derecho Emergente ${ }^{\prime \prime}$, destaca-se neste estudo a segurança ambiental, a qual se funda no entendimento de que a humanidade está vivendo de forma tal que permite afirmar que o planeta está no limite da capacidade de suporte dos seus ecossistemas.

Esta constatação feita pelos cientistas que estudam o meio ambiente impõe ao poder público, empresas e sociedade civil atuarem conjuntamente na busca da proteção ambiental, integrando conservação e desenvolvimento.

O Brasil já incorporou ao seu ordenamento esta concepção, conforme se pode verificar em face da proteção ambiental garantida em nível constitucional, conforme Art. 225 e em especial o Art. 170, VI que determina a intervenção estatal sobre a ordem econômica por meio normativo, fiscalizatório e de incentivo para e efetividade deste direito fundamental.

\footnotetext{
${ }^{4}$ PEREIRA, Juan Pablo Fernández. La Seguridad Humana. Un Derecho Emergente. Barcelona: Ariel, 2006.
} 
Portanto, entre as formas interventivas referidas buscam-se aquela(s) de maior efetividade, ou seja, qual(is) seria(m) a(s) política(s) pública(s) com o objetivo de concretizar os fins almejados pela segurança ambiental.

Considerando a racionalidade econômica da eficiência, indica-se a possibilidade de utilizar o tributo, por meio da extrafiscalidade, pois as normas de estimulo ou de desestimulo poderá se incentivar ou impor condutas ambientalmente favoráveis para a qualidade da vida presente e futura.

A pesquisa analisa os aspectos extrafiscais do IPI, ICM e IPTU para identificar a possibilidade de utilização de uma tributação ambientalmente orientada.

\section{Segurança humana e segurança ambiental}

Pode-se dizer que a segurança humana foca o indivíduo e não o Estado, como o sujeito da segurança, sendo que o Estado é o meio pelo qual o indivíduo pode ter o seu bem estar, liberdade, bem como seus direitos fundamentais garantidos e efetivados.

O conceito de Segurança Humana surgiu com o fim da Guerra Fria (Oliveira, 2009, p. 68), consolidando-se uma nova agenda internacional intensificada pelo processo de globalização, processo este que altera profundamente a ordem internacional e contribui de uma forma decisiva para a reformulação do conceito de segurança internacional. Em 1994, o Programa de Desenvolvimento das Nações Unidas (PNUD) definiu em seu relatório anual o conceito de Segurança Humana.

O conceito de segurança humana tem quatro características principais: a) é centrada nas pessoas, tem como foco da segurança o indivíduo; b) é de interesse universal; c) seus componentes são interdependentes; d) é mais fácil de garantir através da prevenção precoce (NEW dimensions of human security, 1994, p. 22, tradução nossa).

O conceito de Segurança Humana encontra-se em fase de construção, tendo em vista que as preocupações da sociedade têm mudado ao longo do tempo. Como se sabe as maiores preocupações dos Estados giravam em torno das ameaças contra sua soberania. Hoje, a preocupação maior esta relacionada aos direitos humanos dos indivíduos que habitam os Estados. A abordagem da Segurança Humana passa a centrar-se na segurança nos seres humanos. 
Embora não haja um consenso quanto a exata definição do termo, a segurança humana vai muito além das noções tradicionais de segurança para concentrar-se em questões como o desenvolvimento e respeito pelos direitos humanos.

A segurança humana traz contribuições tanto no plano da segurança como no de desenvolvimento humano, tendo em vista que busca o bem-estar dos indivíduos. Para atingir o desenvolvimento humano faz-se necessário a aplicação de políticas públicas nacionais e internacionais com vista a atingir os fins almejados pela segurança humana.

O Capítulo 2 do Relatório de Desenvolvimento Humano (NEW dimensions of human security,1994, p. 24 à 33, tradução nossa) identifica as seguintes dimensões de segurança: Segurança Econômica, Segurança Alimentar, Segurança Sanitária, Segurança Ambiental, Segurança Pessoal, Segurança Comunitária e Segurança Política.

Destaca-se, para o presente trabalho, a segurança ambiental. Segundo o relatório, a falta de água é uma das maiores ameaças nos países em desenvolvimento e a escassez da água é cada vez mais um fator de conflitos étnicos e políticos.

O documento menciona que quase dois bilhões de pessoas carecem de acesso ao saneamento básico o que influencia na poluição das águas. O documento também menciona acerca do desmatamento acelerado e os métodos de conservação desfavoráveis ao meio ambiente. Aponta que muitos desastres naturais têm sido provocados pelos seres humanos. O desmatamento tem levado a secas mais intensas e inundações. Igualmente, a pobreza e a falta de terra estão fazendo com que a população habite áreas que aumentam a exposição aos perigos naturais. $O$ resultado: as catástrofes são mais significativas e mais freqüentes.

No atual contexto internacional, tornam-se interessantes as contribuições que a segurança humana pode trazer para confrontar as ameaças contra o meio ambiente, uma vez que o conceito de segurança humana nos leva a crer que a preservação do meio ambiente é uma preocupação global e que todos estão envolvidos.

Depende da ação dos governos, da sociedade civil (terceiro setor) e das empresas, os governos devem intervir nas relações jurídicas econômicas para possibilitar a dimensão ambiental, intervir nos termos do art. 174 da Constituição Federal de 1988, por meio normativo, fiscalizador, do incentivo e do planejamento.

A questão ambiental não se submete aos limites territoriais, ela busca a prevenção e a proteção de danos ambientais. No ordenamento jurídico brasileiro tem-se, em nível 
constitucional, positivado a dimensão da Segurança Ambiental, conforme se constata: princípio norteador da atividade econômica (Art. 170,VI); exigência para caracterizar a função social da propriedade rural (Art. 186, I e II ); proteção ambiental para a qualidade da vida presente e futura (Art. 225), entre outros dispositivos. Dessa forma, é dever do Estado, da sociedade civil e das empresadas cumprirem os dispositivos constitucionais em busca de um desenvolvimentos sustentável, isto é, respeitando o meio ambiente.

\section{Responsabilidade estatal, social e empresarial pela segurança humana}

A responsabilidade pela segurança humana recai sobre todos aqueles que com ela têm relação, demandando, dessa forma, uma atuação conjunta do Poder Público (10 setor), da sociedade civil ( 3 o setor) e das empresas (2o setor). A busca pela justiça social, portanto, é de responsabilidade estatal, empresarial e da sociedade civil.

A responsabilidade de fornecer a segurança humana cai em primeiro lugar sobre os Estados. Um Estado verdadeiramente eficaz é aquele que desempenha um papel central na vida econômica e social.

Para entender a responsabilidade do Estado na efetividade da segurança humana, faz-se necessário compreender as atribuições do Estado na sociedade. Ao tratar desse assunto Bassoli (2008, p. 123) afirma que: “É a partir do texto constitucional que será possível identificar o "quantum" de direitos e deveres que os membros da nação transferiram ao Estado (...)".

É possível recorrer a este critério para identificar as diferentes formas de intervenção do Estado na sociedade em busca da proteção dos indivíduos às ameaças. $O$ papel do Estado perante a sociedade com o fim de realizar os valores e regras pretendidos pela segurança humana evoluiu ao longo do tempo e ao sabor das ideologias dominantes.

O que marcava o liberalismo clássico era a quase neutralidade do Estado em face da organização econômica, que se traduzia em um grau mínimo de interferência. O ideal de liberdade e individualismo na atividade privada acabou por gerar problemas econômicos, como, por exemplo, a exclusão social advinda da concentração de riquezas, por esse motivo, o Estado se viu forçado a alterar seu papel no cenário social.

O liberalismo passa por transformações permitindo a intervenção estatal em setores estratégicos, surge, dessa forma, o neoliberalismo, o qual apresenta uma dualidade: 
de um lado, preserva a liberdade econômica, de outro, impõe ao Estado a implementação de determinados objetivos para o alcance de determinados fins

O que evoluiu desde o liberalismo clássico, passando pelo Estado social, até o neoliberalismo é o entendimento sobre o grau, o objetivo e o modo de interferência e atuação do Estado na organização econômica, que demarcaram a área de inserção na qual atua o Estado.

A intervenção do governo nos Estados sociais é maior tendo em vista que o Estado social tenta superar a desigualdade social intervindo por meio de ações concretas. O Estado social possibilita a intervenção para a viabilização dos direitos fundamentais. Como principal característica do Estado social, verifica-se sua intervenção nas atividades econômicas, de forma a regular a economia com o fim de se alcançar a justiça social.

A Constituição Federal de 1988, em seu artigo 3o consigna como objetivos fundamentais do Estado brasileiro: construir uma sociedade livre, justa e solidária, garantir o desenvolvimento nacional e etc.

Verifica-se, portanto, que é obrigatória a participação do Estado para viabilizar a segurança humana. Tal obrigatoriedade esta prevista na Constituição Federal. Não sendo, portanto, um poder discricionário do Estado cumprir as normas de nível constitucional

Não é somente o Estado que será responsável pela segurança humana. "As pessoas se organizam para enfrentar os riscos presentes na sociedade de rico global" (Bassoli, 2008, p. 124). Normalmente as pessoas são motivadas pela insuficiência da atuação estatal e pela necessidade de uma ação para combater às ameaças presentes na sociedade.

Em decorrência da carência do Estado a sociedade civil começou a ajudar nas questões sociais por meio de instituições voluntaristas e sem fins lucrativos que compõem o chamado terceiro setor, que vêem desempenhado um papel fundamental na realização dos fins almejados pela segurança humana.

Elas atuam em caráter complementar ao Estado, contribuindo de forma eficaz para a justiça social motivadas pela necessidade premente de melhores condições ambientais, sociais e econômicas de vida para todos.

A Declaração do Rio de Janeiro sobre Meio Ambiente e Desenvolvimento (1992), mais conhecida como Agenda 21 ou ECO-92 coloca em muitas passagens a coletividade 
como importante colaboradora no processo de desenvolvimento, como por exemplo, no princípio 10, o qual dispõe que:

\section{PRINCÍPIO 10}

O melhor modo de tratar as questões ambientais é com a participação de todos os cidadãos interessados, em vários níveis. No plano nacional, toda pessoa deverá ter acesso adequado à informação sobre o ambiente de que dispõem as autoridades públicas, incluída a informação sobre os materiais e as atividades que oferecem perigo em suas comunidades, assim como a oportunidade de participar dos processos de adoção de decisões. Os Estados deverão facilitar e fomentar a sensibilização e a participação do público, colocando a informação à disposição de todos. Deverá ser proporcionado acesso efetivo aos procedimentos judiciais e administrativos, entre os quais o ressarcimento de danos e os recursos pertinentes.

Bem como o Estado e a sociedade civil, as empresas devem participar na busca da justiça social pretendida pela segurança humana para colaborar ativamente com soluções que fomentam o desenvolvimento sustentável.

A idealização do liberalismo econômico que perseguia a maximização dos lucros e dizia que as empresas deveriam produzir com eficiência bens e serviços e deixar as questões sociais para os órgãos governamentais mudou, tendo em vista que tal atividade industrial voltada apenas ao lucro gerou efeitos negativos, como os problemas ambientais e a precariedade das relações de trabalho.

A partir desse momento a sociedade começou a se mobilizar para pressionar as empresas a buscarem soluções para os problemas gerados pela industrialização. Dessa forma, o conceito de responsabilidade social empresarial passou a incorporar alguns anseios da sociedade. As empresas devem buscar uma atuação no mercado de forma sustentável, isto é, as empresas não podem apenas visar o lucro, deve haver inclusão social e respeito ao meio ambiente.

A Constituição Federal em seu art. 170 define o regime jurídico que deve nortear as ações empresárias diante do domínio econômico, a Constituição Federal contemplou uma ordem econômica distanciada de um modelo liberal puro e ajustada à ideologia neoliberal, a liberdade é admitida apenas enquanto exercida no interesse social (SILVA, 2007, p. 785-790).

Verifica-se que a Constituição Federal reconhece a ordem econômica fundada na liberdade de iniciativa e o exercício de atividade ou profissão, porém tal liberdade não pode comprometer a justiça social. Impõem-se alguns limites a esta liberdade tais como: "[...] submeter-se à soberania nacional; usar a propriedade com função social; condutas que 
viabilizem a livre iniciativa e a concorrência; respeitar as relações de consumo; atuar conforme as normas que protegem o meio ambiente [...]" (BASSOLI, 2008, p. 126).

Os princípios introduzidos na Ordem econômica são os alicerces necessários para que a atividade econômica possa alcançar a dignidade humana e possibilitar o bem-estar social. Se os agentes econômicos desrespeitarem tais princípios cabe ao estado intervir na atividade econômica (estado neoliberal), para que o equilíbrio possa ser restabelecido.

\section{Intervenção do estado sobre o domínio econômico em pról da segurança ambiental}

O papel do Estado é de grande importância para a obtenção de qualquer forma de desenvolvimento, abrangendo a expressão em todos os seus níveis, tanto social quanto econômico, bem como o ambiental.

O Estado é uma evolução da sociedade, compondo uma estrutura desenvolvida para ordenar o convívio humano. Com o desenvolvimento das relações sociais, econômicas e jurídicas, o papel do Estado foi se transformando no contexto histórico influenciado por ideologias. O papel do Estado como agente regulador das relações econômicas alterou de acordo com os fins ideológicos construídos ao longo da história, isto é, o entendimento sobre o grau, o objetivo e o modo de intervenção do Estado nas relações econômicas evoluiu ao longo do tempo.

No Brasil, deve ser analisado a passagem do Estado De Direito, isto é, o Estado influenciado pelos ideais liberais para o Estado Democrático de Direito, que busca conciliar o Estado de Direito com um Estado Social.

O Estado liberal, construído pelos ideários do liberalismo clássico iniciado no século XVIII, preservava a liberdade econômica, ou seja, a atividade econômica no ordenamento liberal deveria ser autosuficiente, a função do Estado era meramente de permitir que a economia não sofresse nenhuma interferência.

Com o final da segunda guerra mundial, surge um novo movimento social caracterizado pelas transformações marcadas por problemas políticos, econômicos e sociais, o Estado passa a intervir nas relações econômicas como forma de suprir as negatividades trazidas pelo Estado liberal surgindo, dessa forma, o Estado Social, cuja característica principal é a permissão do Estado intervir na ordem econômica com o fim de assegurar os direitos econômicos e sociais. 
A Constituição da República de 1988 trouxe uma vasta gama de princípios do Estado Social em consonância com os princípios capitalistas do Estado Liberal. Adotou um sistema econômico apoiado na livre iniciativa, na liberdade de contratar, na livre concorrência e na propriedade privada, porém a Constituição enuncia diretrizes, programas e fins a serem realizados pelo Estado e pela sociedade para regular a ordem econômica.

Analisado a evolução dos pensamentos econômicos acerca da intervenção estatal, passa-se a analisar a intervenção do Estado brasileiro nas atividades econômicas em prol da segurança ambiental.

A intervenção do Estado sobre o domínio econômico

A atuação do Estado sobre a economia se dá através de um sistema jurídico que pode ser chamado de constituição econômica, que expressa um conjunto de diretrizes jurídico-normativas destinadas a estabelecer como deve ser a organização econômica, ou seja, no que se consubstancia a Ordem Econômica Constitucional. Em termos amplos, a constituição econômica estabelece o conjunto de normas voltadas à organização econômica.

O art. 170 da Constituição proclama de forma explícita, os valores buscados pela ordem econômica, ao programar tais fins o constituinte estabeleceu os meios e as condições a serem utilizados, os quais encontram previstos no art. 173 e 174 da Carta Magna.

Os princípios inseridos na ordem econômica constitucional (art. 170, CF) são os alicerces necessários para que a atividade econômica possa alcançar os direitos que possibilitem a segurança humana e em consequência a segurança ambiental, tendo em vista que um dos princípios elencados no art. 170 da CF, é a defesa do meio ambiente. Assim, competirá ao Estado intervir nas relações econômicas em busca da realização de tais princípios.

São duas modalidades de intervenção do Estado sobre o domínio econômico, o estado poderá intervir no campo econômico diretamente ou indiretamente. $\mathrm{O}$ art. 173 da CF estabelece a forma de intervenção direta, isto é, o Estado age diretamente no campo econômico por meio da criação de empresa pública ou sociedade de economia mista. Esta modalidade de intervenção só é permitida quando necessária aos imperativos de segurança nacional ou relevante interesse coletivo. 
$\mathrm{Na}$ intervenção indireta, o Estado dirige e controla a economia privada. As possibilidades de intervenção do Estado sobre o domínio econômico estão elencadas no art. 174 da Constituição Federal, o Estado pode intervir nas relações econômicas por meio normativo, por meio de normas que incentivem, por meio da fiscalização e por meio de planejamento.

Por meio normativo o Estado atua por meio do Poder Legislativo, editando leis que disciplinem as relações econômicas de forma a condicioná-las aos princípios da livre iniciativa, da defesa do consumidor, da defesa do meio ambiente e etc., são exemplos disso o Código de Defesa do consumidor (art. 5ㅇ, inc. XXXII, CF), a lei de repressão ao abuso do poder econômico (art. 173, § 4으, CF), entre outras.

Por meio de normas que incentivem o Estado intervém sobre domínio econômico por via do fomento, ou seja, apoiando a iniciativa privada e estimulando determinados comportamentos, objetivando o aumento das externalidades positivas. Assim, por exemplo, o Estado pode usar de certos mecanismos, como o tributário, para procurar condicionar ou provocar determinados comportamentos, em acordo com o art. 174 da Constituição Federal.

Por meio da fiscalização o Estado atua através do órgão executivo, em tal hipótese o Estado age exercendo poder de polícia atuando para que as normas interventivas sejam cumpridas, de forma a manter o equilíbrio econômico, preservar a livre iniciativa e a concorrência, bem como a proteção do meio ambiente.

Por meio do planejamento é a possibilidade do Estado intervir através de criação de diretrizes que regulamentam as políticas públicas, que normalmente têm forte influencias na definição das políticas empresariais.

Observa-se que o Estado possui diversos instrumentos capazes de interferir na atividade econômica, de modo e possibilitar a efetividade dos princípios constitucionais previstos no art. 170, de modo a garantir a todos uma existência digna.

Verifica-se, portanto, que é dever-poder do Estado intervir nas relações econômicas por meio do processo de positivação, de fiscalização, de incentivo e de planejamento para estabelecer diretrizes que regule as relações econômicas permitindo a livre iniciativa e a livre concorrência, desde que atenda aos ditames da segurança humana.

No exercício da função reguladora e normativa da atividade econômica, no binômio dever-poder é que o Estado faz uso do tributo ambientalmente orientado, como forma de 
regulamentar a atividade econômica de forma sustentável. Trata-se de um poder-dever do Estado intervir na ordem econômica para tal fim, não é um ato discricionário do mesmo.

A proteção do meio ambiente como princípio da atividade econômica

O artigo 170 da Constituição Federal reúne as diretrizes fundamentais da Ordem Econômica, das quais se denota que a atividade econômica deve ser organizada de forma a causar menor impacto possível ao meio ambiente.

Os princípios da ordem econômica ao determinarem a realização de fins sociais, através de programas de intervenção na ordem econômica com vistas à realização da justiça social, revelam como instrumentos de grande eficácia na busca da justiça social.

Em outros termos, o princípio da defesa do meio ambiente subordina a atividade econômica.

Os instrumentos jurídicos de caráter legal e de natureza constitucional objetivam viabilizar a tutela efetiva do meio ambiente, o art. 225 da Constituição Federal estabeleceu valores de proteção ao meio ambiente que permitem o real controle pelo Estado das atividades econômicas, o qual deve promover políticas públicas que harmonizem os objetivos econômicos com a proteção ambiental.

No título da Ordem Econômica e Financeira, a Constituição arrola, dentre os princípios gerais da atividade econômica, "a defesa do meio ambiente, inclusive mediante tratamento diferenciado conforme o impacto ambiental dos produtos e serviços e de seus processo de elaboração e prestação" (art. 170, VI da Constituição Federal). Dessa forma, para atingir tal propósito, pode o legislador valer-se de instrumentos e ferramentas que encontra à disposição, inclusive normas tributárias, para induzir ou inibir comportamentos desejáveis.

É certo que a preservação do meio ambiente deve condicionar a atividade econômica, isto é, os agentes econômicos devem atuar de modo compatível com um meio ambiente saudável.

Considerando que só haverá desenvolvimento econômico com a proteção do meio ambiente, é dever do Estado intervir sobre as relações econômicas com o objetivo de minimizar as externalidades negativas ao meio ambiente, de modo a estimular a atuação dos 
agentes econômicos de forma harmônica com o meio ambiente em busca de um desenvolvimento econômico sustentável.

É papel de todos, Estado e sociedade, buscarem alternativas aos modelos de exploração da atividade econômica, para atingir o desiderato consagrado pela Constituição Federal, de forma a conciliar a preservação ambiental e o desenvolvimento econômico, tomando tais atitudes é possível vivenciar o desenvolvimento econômico sustentável.

Para alcançar o desenvolvimento sustentável é necessário um planejamento do Estado, bem como o reconhecimento de que os recursos ambientais são finitos. Assim, os agentes econômicos precisam atuar dentro dos limites da capacidade de suporte dos ecossistemas.

Faz-se necessário, por outro lado, a atuação do Estado, regulando e fiscalizando a aplicação das normas ambientais, o intervencionismo fiscal serve de instrumento eficaz para a reforma ou educação socioambiental.

Dentre os instrumentos à disposição do Estado para a intervenção sobre o domínio econômico objetivando a defesa do meio ambiente, encontra-se o sistema tributário.

A aplicação da tributação na defesa do meio ambiente está diretamente relacionada com a idéia do princípio do poluidor pagador, a saber, possibilita-se alterar o custo de utilização dos recursos ambientais internalizando as externalidades e, dessa forma, afetar seu nível de utilização.

Seria esse o sentido do princípio 16 da declaração do Rio para o meio ambiente e o desenvolvimento:

Princípio 16: "Tendo em vista que o poluidor deve, em princípio, arcar com o custo decorrente da poluição, as autoridades nacionais devem procurar promover a internalização dos custos ambientais e o uso de instrumentos econômicos, levando na devida conta o interesse público, sem distorcer o comércio e os investimentos internacionais".

Desta forma, admiti-se a possibilidade de criação por parte do poder público de um conjunto de medidas econômicas e administrativas que possam impor aos empreendedores potencialmente poluidores uma conduta que condiz com os propósitos almejados pela Constituição Federal em seu art. 225. Os tributos ambientais buscam adequar a atuação das 
atividades econômicas poluidoras, de forma a estimulá-las a atuem em harmonia com o meio ambiente.

Deve agregar ao custo do produto ou do processo produtivo de determinado bem as externalidades negativas produzidas pela produção, de forma a desestimular os consumidores a adquirirem bens potencialmente poluidores ao meio ambiente, uma vez que a agregação de tal custo fará com que o produto tenha um preço elevado.

A conduta das atividades econômicas irá mudar, tendo em vista que as empresas buscarão alternativas ambientalmente corretas para que aquele produto possa ter uma redução de preço, de forma a estimular seus consumidores a adquirirem produtos que não degradam a natureza.

Percebe-se que a tributação ambiental pode atuar de suas formas: primeiramente como forma de induzir determinado comportamento social, objetivando influenciar as empresas a atuarem em harmonia com o meio ambiente e os consumidores a adquirirem produtos ambientalmente corretos e, de forma a gerar recursos para o financiamento de políticas públicas voltadas a proteção ambiental.

Políticas públicas e políticas públicas tributárias para a preservação do meio ambiente

A intervenção do Estado sobre a ordem econômica como agente regulador das atividades econômicas deve tomar por base o princípio da defesa do meio ambiente. 0 estado pode intervir na atividade econômica por meio do planejamento, isto é, elaborando políticas públicas de preservação ambiental, a utilização desse instrumento deve se feito de acordo com suas respectivas características e finalidades.

Não obstante, as atividades econômicas geram impactos sobre meio ambiente, para minimizar os impactos sobre o bem-estar dos indivíduos o Estado lança mão das políticas públicas para preservação do meio ambiente, de maneira a conciliar desenvolvimento econômico com defesa ambiental.

As políticas públicas traduzem os meios necessários para atingir os valores estabelecidos pelos princípios jurídicos que vinculam as finalidades a serem alcançadas pela sociedade, por exemplo, o princípio da defesa ambiental. A tributação ambiental apresentase como um instrumento de política pública ambiental eficaz para atingir os objetivos do inc. VI do art. 170 da Constituição Federal. 
A tributação ambiental é uma forma de política pública com o objetivo de implementação de políticas de proteção ao meio ambiente e ao desenvolvimento sustentável.

Mediante a tributação ambiental os agentes econômicos poluidores tendem a diminuir as atividades causadoras de impacto ambiental, buscando novas técnicas para utilização de produtos menos poluidores e mais eficientes, com o objetivo de diminuir a carga tributária suportada, uma vez que os agentes econômicos que contribuem para o desequilíbrio ambiental terão que suportar uma carga fiscal maior.

Por meio da tributação ambiental é possível implementar uma política efetiva de proteção ao meio ambiente, com a utilização das espécies tributárias, quer para arrecadar recursos aos órgão públicos para serem utilizados na promoção de políticas públicas voltadas ao meio ambiente, quer para influenciar o comportamento dos contribuintes em face ao meio ambiente.

A tributação ambiental pode ter como objetivo internalizar os custos ambientais das atividades lícitas que sejam nocivas ao meio ambiente. Tal função é precisamente trazer para o custo de cada bem ou mercadoria o custo que seu consumo representa em termos ambientais, isto é, internalizando no produto as externalidades negativas causadas pelo produto ou seu processo de formação afetando, assim, seu nível de utilização.

Buscando um melhor resultado econômico, os agentes poluidores sentem-se impulsionados a procurarem novas técnicas e meios de produção que permitem uma redução da poluição ambiental ou até mesmo a extinção de tal poluição. Os agentes poluidores terão que conciliar a exploração econômica com a preservação ambiental.

Os impostos extrafiscais podem ser utilizados como instrumentos de tributação no campo ambiental. Por meio dos mecanismos de graduação das alíquotas, reduções de base de cálculo e seletividade é possível estimular ou desestimular a produção de produtos nocivos ou benéficos ao meio ambiente. Tal técnica possibilita o estímulo à pesquisa e investimentos em tecnologias na exploração de recursos renováveis alternativos, bem como, diminui os desastres ecológicos e reduz os gastos públicos com recuperação ambiental e saúde pública

Ademais, não é necessário a criação de impostos novos, mas sim a aplicação de impostos existentes visando a defesa do meio ambiente. Conforme se verá no próximo 
capítulo, pode a extrafiscalidade estar relacionada aos impostos de consumo, por exemplo, o ICMS e o IPI, cuja seletividade também leva em conta a essencialidade dos bens em função da degradação ambiental.

\section{Intervenção do Estado Por Meio da Extrafiscalidade em Prol da Segurança} Ambiental

A intervenção do Estado como ente ordenador da atividade econômica em função da proteção ambiental é de grande importância. Dentre os instrumentos que possibilitam a intervenção do Estado está o sistema tributário. No que respeita ao meio ambiente, a possibilidade de se utilizar o tributo como instrumento de sua proteção está diretamente relacionada à aplicação da técnica da extrafiscalidade tributária. A tributação pode servir de instrumento à realização dos propósitos da segurança ambiental.

A extrafiscalidade constitui um meio de o Estado utilizar a tributação como instrumento de intervenção da sociedade, sobretudo no campo econômico e social, com vistas a concretizar as diretrizes constitucionalmente previstas.

Cabe frisar que a extrafiscalidade não significa que o Estado deixe de arrecadar tributo. A finalidade da extrafiscalidade não é meramente arrecadatória, ainda que ingressem recursos aos cofres públicos. Visa, pois, direcionar o comportamento dos agentes econômicos aos objetivos constitucionalmente positivados. Dessa forma, verifica-se ser possível a utilização da extrafiscalidade como forma de concretização dos objetivos traçados pela segurança ambiental

O intervencionismo estatal por meio da extrafiscalidade constitui um eficiente instrumento na preservação e combate à poluição. É dever do Estado intervir na ordem econômica com o fim de garantir um meio ambiente ecologicamente equilibrado.

Esta forma de tributação está intimamente relacionada com o princípio do poluidorpagador, tendo em vista que ela visa graduar a tributação, incentivando as atividades e consumos não-poluidores e desestimulando a produção e consumo de bens ecologicamente incorretos.

Por meio da agravação da carga tributária, podem-se afastar certas atividades reputadas contrárias ao meio ambiente. Dessa maneira, a extrafiscalidade por servir tanto 
para coibir comportamentos lesivos ao meio ambiente, como também para estimular condutas ambientalmente corretas.

\section{Extrafiscalidade por meio do IPI}

O art. 153, IV, da Constituição Federal confere competência à União para a instituição de imposto sobre Produtos Industrializados. Tal imposto incide sobre as operações com produtos industrializados.

A Constituição Federal, no seu art. 153, § 3o, determina a observância da técnica da seletividade na instituição do IPI, a seletividade implica uma tributação diferenciada conforme a qualidade do produto. $\mathrm{O}$ uso do critério da seletividade no IPI deve ser observado pelo ente competente para a sua instituição (no caso, a União) não se trata de um poder discricionário e sim de uma imposição constitucional. Diante disso, as alíquotas devem variar conforme a essencialidade do produto.

Por meio dos princípios constitucionais (art. 153, § 3ㅇ, CF) da seletividade, o Imposto sobre Produtos Industrializados (IPI), previsto no art. 46 do Código Tributário Nacional, pode obter uma função extrafiscal ambiental. A seletividade implica a tributação diferenciada conforme a qualidade do que é objeto da tributação.

Com a aplicação da extrafiscalidade por meio do IPI, o poder público poderá orientar comportamento dos agentes econômicos de modo a preservar o meio ambiente. As alíquotas seletivas, de acordo com a essencialidade do produto serão fixadas pelo Poder Executivo, que adotará tal técnica de tributação por ocasião da elaboração da Tabela de Incidência do Imposto sobre Produtos Industrializados, a TIPI.

Leandro Paulsen (2009, p. 80) afirma que na TIPI: “Serão identificados os produtos e atribuídas as respectivas alíquotas, sendo que o critério para a variação tem de ser a essencialidade do produto. Poderá ser atribuída, inclusive alíquota zero para determinados produtos, se assim entender o Executivo"

Considerando que o IPI pode ter uma função extrafiscal voltada à proteção do meio ambiente, um produto não pode ser entendido como essencial, quando o seu consumo provoque degradação ambiental, razão pela qual poderá ter suas alíquotas majoradas para desestimular o consumo. 
A seletividade ambiental do IPI encontra respaldo na proposta de uma Reforma Tributária Ambiental constante na PEC 353/20095. Uma das propostas inseridas pela PEC 353/2009 é a introdução da extrafiscalidade ambiental do IPI, conforme estabelece a proposta de introdução de um § 5--A no art. 153 da Constituição Federal, com a seguinte redação:

\footnotetext{
“art. 153. Compete à União instituir impostos sobre:

IV - produtos industrializados

§ 50-A. Os impostos previstos neste artigo, sempre que possível, orientar-se-ão pela seletividade socioambiental e terão suas alíquotas fixadas em função da responsabilidade socioambiental das atividades desempenhadas pelo contribuinte"
}

Importante ressaltar ainda a existência do Decreto Federal no 755/93, que estabeleceu diferentes alíquotas no imposto sobre produtos industrializados (IPI) para carros a gasolina, a álcool e a bicombustível. Os carros à gasolina possuem uma alíquota maior $(9,5$ $\%)$, tendo em vista que poluem mais o meio ambiente. Por outro lado, os carros movidos a álcool e a biocombustível (7,5 \%) terá a alíquota do IPI reduzida, o que estimula o consumo de combustível não poluente. Essas ações pretendem estimular um menor consumo de energia para preservar o meio ambiente, o que significa reduzir a emissão de gases na atmosfera.

O objetivo é que haja uma um estímulo na produção de veículos menos poluentes, o que levará a indústria automobilística brasileira a um novo nível tecnológico, uma vez que terá que oferecer alternativas de produtos ambientalmente corretos.

Tal técnica também é aplicada aos caminhões, que terá isenção completa da alíquota até o mês de junho de 2010, o objetivo é estimular a renovação da frota brasileira, associada à preservação ambiental, visa estimular a criação de tecnologias menos poluentes, como, por exemplo, a implementação de carros híbridos (energia elétrica e renovável).

Além dos estímulos para o consumo de carros menos poluentes, há no Brasil uma redução nas alíquotas do imposto sobre produtos industrializados (IPI) dos eletrodomésticos com selos de classe A e B (que consomem menos energia).

\footnotetext{
5 Proposta de Emenda à Constituição $\mathrm{n}^{\mathrm{o}} 353$ de 2009. Disponível em $<$ http://www.reformatributariaambiental.com.br/reforma_tributaria_ambiental.html $>$. Acesso em 15 de maio de 2010.
} 
Deve-se pensar, portanto, em uma essencialidade ambiental, a seletividade deve levar em conta o nível de poluição do produto, incentivando desta forma, a comercialização de produtos não-poluentes.

\section{Extrafiscalidade por meio do ICM}

O ICMS - imposto incidente sobre as operações relativas à circulação de mercadorias e sobre prestações de serviços de transporte interestadual e intermunicipal e de comunicação é tributo de competência dos Estados e do Distrito Federal.

O ICMS também pode ser seletivo (art. 155, § 2으, III) em função da essencialidade das mercadorias e serviços, permitindo, desse modo, a adoção de alíquota mais gravosa para as operações com mercadorias poluentes ou tóxicas.

Considerando a possibilidade de utilizar a seletividade no ICM, tal tributo pode ter uma função extrafiscal ambiental, sendo possível, por exemplo, incentivar a circulação de produtos ecologicamente corretos através de uma redução da alíquota de tais operações. Esse incentivo pode partir de políticas tributárias de incentivos fiscais através da extrafiscalidade do ICM.

O emprego da seletividade no ICM constitui uma relevante ferramenta para a proteção e preservação do meio ambiente, com o objetivo de aumentar o consumo e a produção de bens que causem um menor impacto ao meio ambiente.

Ademais, o ICM é considerado um imposto indireto, isto é, o valor do tributo é repassado ao consumidor final, dessa forma, é possível estabelecer uma política tributária ambiental voltada aos consumidores, de forma a estimular os mesmos a realizar operações com mercadorias que guardem uma vinculação com a proteção ambiental, tendo em vista que tais operações podem ter uma tributação reduzida, em função da seletividade ambiental, por exemplo.

Assim, pode-se dizer que o uso seletivo do ICM com o escopo de proteção ao meio ambiente direcionará o produtor a adotar condutas ecologicamente mais adequadas, uma vez que a incidência de carga fiscal elevada sobre um produto não ecologicamente correto fará com que este se torne mais caro em face de um produto concorrente que seja ambientalmente correto. 
Logo, a imputação dos custos ambientais tem como fim o produtor, tendo em vista que ao consumidor não resta alternativa para reduzir a poluição, senão deixar de consumir determinado bem. Em contrapartida, os produtores podem buscar alternativas de produção menos poluentes.

Por meio do ICM é possível o Poder Público conceder benefícios fiscais aos contribuintes que tiverem condutas ambientalmente corretas nas operações relativas à circulação de mercadorias e prestação de serviços.

Diante disso, verifica-se que não há óbice para que o ICM tribute, por exemplo, de modo menos oneroso, operações mercantis com produtos ecologicamente corretos, que não agridem o meio ambiente. No mesmo sentido, a desoneração do ICMS ao fabricante de papel reciclável.

\section{Extrafiscalidade por meio do IPTU}

A instituição do Imposto sobre a Propriedade Predial e Territorial Urbana é de competência exclusiva do Município (art. 156, inc. I, da CF). A Constituição determina que o IPTU poderá ter alíquotas diferentes de acordo com a localização e o uso do imóvel (art. 182,

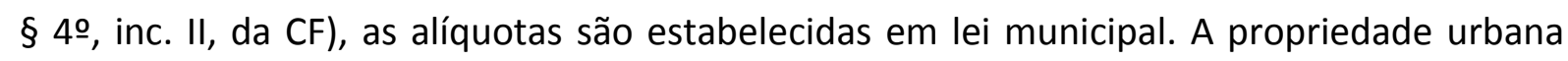
deve observar sua função social mediante a preservação do meio ambiente.

Importante referir que a Constituição Federal em seu art. 5o, inc. XXIII, determina que a propriedade deverá atender a sua função social. Ademais, o artigo 1.228 do Código Civil, menciona além da função social da propriedade, a função sócio-ambiental da propriedade.

\footnotetext{
"Artigo: 1.228. O proprietário tem a faculdade de usar, gozar e dispor da coisa, e o direito de reavê-la do poder de quem quer que injustamente a possua ou detenha. $\S 1^{\circ} \mathrm{O}$ direito de propriedade deve ser exercido em consonância com as suas finalidades econômicas e sociais e de modo que sejam preservados, de conformidade com o estabelecido em lei especial, a flora, a fauna, as belezas naturais, o equilíbrio ecológico e o patrimônio histórico e artístico, bem como evitada a poluição do ar e das águas".
}

O uso do IPTU como instrumento de desenvolvimento econômico com vista ao atendimento da função social da propriedade, faz com que seja possível ao Município 
editar uma lei que estabeleça, por exemplo, a elevação das alíquotas do IPTU dos imóveis urbanos utilizados como sedes industriais localizados na região central da cidade.

Tal política tributária, voltada para a progressividade do IPTU, objetiva tributar com alíquotas diferenciadas (carga tributária menor) aqueles imóveis urbanos que adotem práticas ambientalmente desejáveis, por exemplo, os contribuintes que façam uso racional dos recursos naturais. Adotando tal técnica, é possível o desenvolvimento de ações relacionadas ao planejamento, coordenação e controle para a preservação do meio ambiente.

No que concerne à orientação ambiental do IPTU, importa destacar a proposta constante na PEC 353/2009, que propor a alteração na redação do art. 156, § 1ㅇ, II, da Constituição Federal, que passaria a ser a seguinte:

\footnotetext{
“Art. 156. § 1 - - Sem prejuízo da progressividade no tempo a que se refere o Art. 182, § 4으, inciso I (progressividade no tempo), o imposto previsto no inciso I (IPTU) poderá:

II - ter alíquotas diferentes de acordo com a localização e o uso do imóvel e o respeito à função socioambiental da propriedade".
}

Assim, o IPTU poderá ter natureza extrafiscal, objetivando estimular a utilização correta da propriedade urbana, de modo a garantir a função socioambiental da propriedade, com vista a preservar o meio ambiente para as presentes e futuras gerações.

Esta autorização constitucional está regulamentada pelo Estatuto da Cidade (Lei 10257/2001) que traz parâmetros para a função social da propriedade urbana, em nível nacional, para que os municípios recorram a esta competência e efetivem esta proteção. Portanto, é necessária, ainda e apenas, a vontade política dos governantes que podem concretizar esta política do Estado brasileiro.

\section{Conclusão}

Este estudo teve por objetivo principal estudar a intervenção estatal sobre a ordem econômica como forma de estabelecer políticas públicas tributaria para a proteção do meio ambiente.

Verificou-se que a os objetivos da segurança ambiental foram cotejados pela Constituição Federal de 1988, ou seja, o ordenamento nacional impõe a necessidade de 
proteção do meio ambiente para a qualidade da vida presente e futura, conforme se depreende da leitura do Art. 225 da Carta Magna e Art. 170,VI, . Neste caso a proteção do meio ambiente constitui um dos princípios da ordem econômica constitucional.

O estudo mostrou que a responsabilidade pela segurança ambiental recai sobre o Estado, sociedade civil e empresas. Diante disso, conforme determinação do art. 174 da CF, é dever do estado intervir sobre o domínio econômico para compelir a todos a atuarem de acordo com a preservação ambiental.

O Estado poderá intervir, seja via fiscalização, planejamento, incentivo ou positivação. É na modalidade de intervenção via normatização e incentivo que o Estado pode elaborar políticas públicas com o objetivo de compelir ou incentivar os agentes econômicos a considerarem condutas ecologicamente corretas.

Nesse diapasão, surge o instrumento da extrafiscalidade como forma do Estado intervir nas atividades econômicas com o escopo de induzir os agentes econômicos a adquirirem condutas que visam à proteção do meio ambiente.

O Poder Público tem na extrafiscalidade uma maneira de conciliar desenvolvimento econômico e a defesa do meio ambiente, pois, com a tributação diferenciada o Poder Público pode estimular comportamentos ambientalmente desejáveis. A tributação ambiental defendida no trabalho serve tanto para coibir comportamentos lesivos ao meio ambiente, como também para estimular condutas ambientalmente corretas;

Verificou-se a possibilidade de utilização da extrafiscalidade por meio do IPI ((Art. 153, § 3ㅇ), ICM (Art. 155, § 2으, III ) e IPTU(Art. 156. § 1으, II) como caminhos viáveis para a preservação ambiental.

\section{Referências}

BASSOLI, Marlene Kempfer. Intervenção do estado sobre o domínio econômico em prol da segurança humana. In: FERREIRA Jussara Suzi Nasser Borges Assis; RIBEIRO, Maria de Fátima. Empreendimentos econômicos e desenvolvimento sustentável. Marília: Arte e Ciência, 2008, p. 109-132.

BRASIL; Constituição (1998). Constituição da república federativa do Brasil. São Paulo: Brasiliense, 1998. 
BRASIL. Ministério do Meio Ambiente. Declaração do Rio sobre o Meio Ambiente e Desenvolvimento. Disponível em <www.mma.gov.br/?id_estrutura=18\&id_conteudo=576>. Acesso em 09.maio.2010

NEW Dimensions of Human Security. Disponível em <http://hdr.undp.org/en/reports/global/ hdr1994/>. Acesso em 30 de março de 2010.

OLIVEIRA, Adriana Bazzano. O Fim da Guerra Fria e Os Estudos da Segurança Internacional: O conceito de Segurança Humana. Disponível em: <www.marilia.unesp.br/home/resvitas eletronicas/autora/OLIVEIRA.pdf. Acesso em: 01 de abril de 2010.

SILVA, José Afonso. Curso de Direito Constitucional. 28a Edição. São Paulo: Editora Malheiros, 2007.

PAULSEN, Leandro. Direito tributário: Constituição e código tributário à luz da doutrina e da jurisprudência. Porto Alegre: Editora Livraria do Advogado, 2009. 